AVOID THE

\section{DREADED REMAKE}

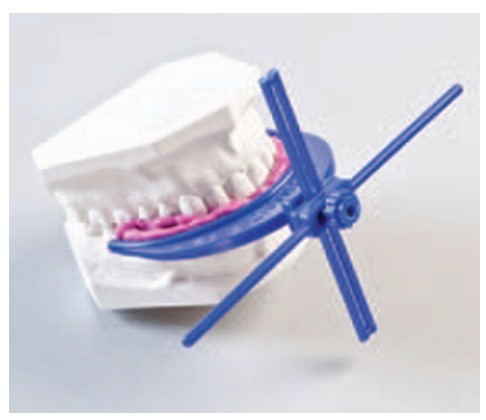

Esthetic CrossRef, available exclusively in the UK from Prestige Dental, enhances communication between the dentist and the laboratory as it accurately records the patient's midline and horizontal plane.

Esthetic CrossRef allows the vertical and horizontal bars to be aligned after the bite registration material sets. This bite record can then be used to mount the casts on any articulator. In addition, it enables the laboratory to do a final check of the completed crowns or veneers by removing the upper bite material and placing the lower impression on the articulated models.

One of the goals of any practice is to provide greater predictability of results. The Esthetic CrossRef provides an easy, inexpensive and predictable solution to one of the greatest frustrations for dentists, patients and laboratory technicians - the dreaded remake.

For more information, contact Prestige Dental by email at info@prestige-dental.co.uk or call 01274721567.

\section{DISTINCTIVELY PREDICTABLE IMPRESSIONS}

GC Europe has harnessed the best qualities of two great materials to form the next generation impression material: Vinyl PolyEther Silicone (VPES).

With EXA'lence GC takes dentistry to a new level by solving a number of common problems related to impression taking, providing distinctively predictable impressions under all conditions.

EXA'lence possesses high elasticity and tear strength, combined with constant hydrophilicity and exceptional flow - the result being one of the most accurate impressions obtainable in the market today. EXA'lence is predictable in an unpredictable environment and virtually eliminates the need for retakes. EXA'lence provides an incredible level of detail that is paramount for optimal-fitting restorations. Every aspect of EXA'lence's unique chemistry is designed to make it the ideal material for every dentist and technician on the path to clinical excellence.

For further information contact GC UK on 01908218999.

\title{
SATISFACTION OR YOUR MONEY BACK
}

Oral-B has launched their WOW campaign on packs of power toothbrushes. They are so confident in their products that if the customer is dissatisfied with the performance of their brushes in any way, they will refund the cost of the unit within 30 days even if they've simply changed their mind. The packs are emblazoned with the reassuring message that 'You'll never go back or your money back'.

Furthermore, whether the pack is purchased in dental surgeries or in retail outlets, the products have the same limited warranty. Providing they have a receipt for their purchase, customers can return the brush within a two-year period in the unlikely event of malfunction. P\&G will either rectify the problem free of charge or provide a replacement product (at no extra cost).
Dissatisfaction based on performance is highly unlikely. The toothbrushes' efficacy at removing plaque, versus a manual toothbrush, is well documented. Studies have shown the Precision Clean brush head to remove up to five times more plaque along the gum line versus a regular manual toothbrush. Not only will it remove more plaque, but the flagship Triumph model also tackles the issue of compliance which measures brushing duration, thoroughness and pressure. For those who prefer the look and feel of a manual toothbrush there's the Oral-B Trizone, which combines a manual brush head design with an electric drive, which performs with a sweeping rather than oscillatingrotating action.

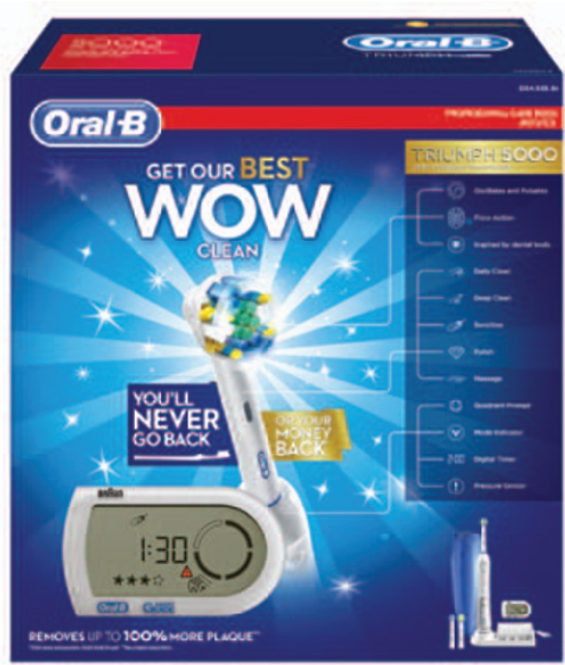

\section{PROBABLY THE MOST ACCURATE IMPRESSION}

The CEREC System takes an optical impression of the preparation and the antagonist, resulting in probably the most accurate impression you will ever have taken. To allow you complete control of the finished prosthesis you specify the positions of the margins and the proximal contacts. The CEREC system goes on to swiftly fabricate the crown, inlay, onlay or veneer accurately, quickly and to the very highest quality. CEREC automatically accurately computes the occlusal contacts referring to the antagonist to do so, resulting in the perfect fit.

The CEREC 3D CAD/CAM System will help you to produce probably the best ceramic restorations possible. You will find the fit to be superb as the margin for error has been removed; the function, wear, durability and aesthetics of a CEREC prosthesis is second to none. In addition, this high-tech piece of equipment allows you to place the new prosthesis in the same visit saving you and your patient time and laboratory fees and any embarrassment at having to wear a temporary.

To find out more and for a demonstration of the CEREC 3D system call 08450715040 or visit www.sironadental.co.uk. 